\title{
Health reform requires policy capacity
}

\author{
Pierre-Gerlier Forest ${ }^{{ }^{*}}$, Jean-Louis Denis ${ }^{2}$, Lawrence D. Brown ${ }^{3}$, David Helms ${ }^{4}$
}

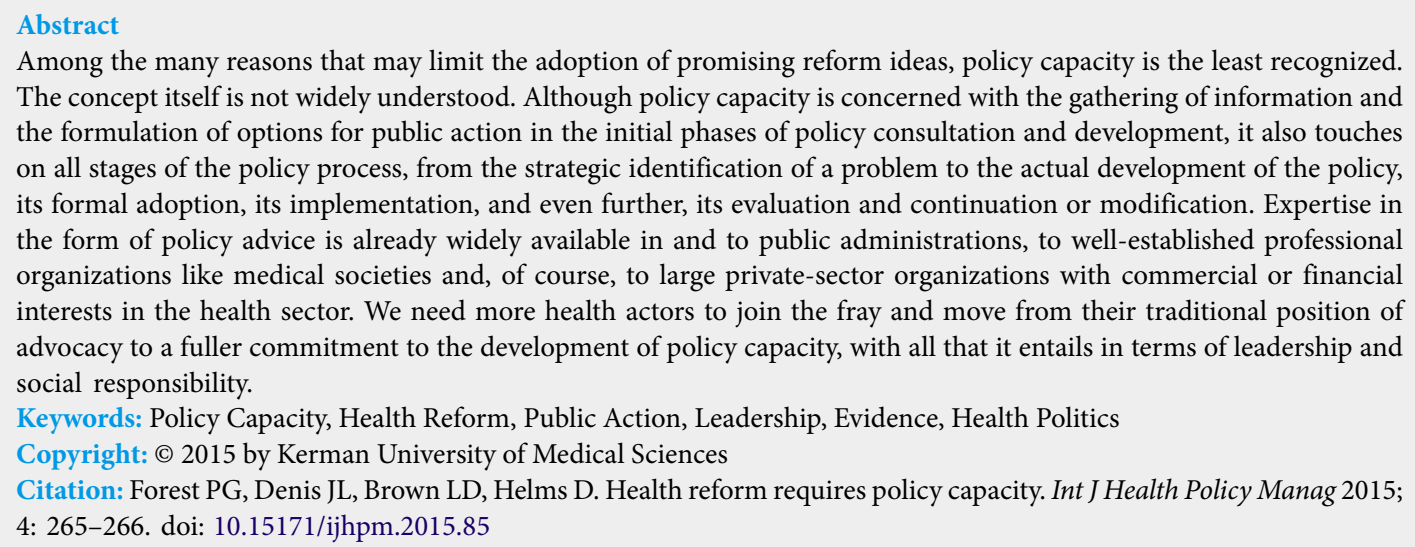

Among the many reasons that may limit the adoption of promising reform ideas, policy capacity is the least recognized. The concept itself is not widely understood. Although policy capacity is concerned with the gathering of information and the formulation of options for public action in the initial phases of policy consultation and development, it also touches on all stages of the policy process, from the strategic identification of a problem to the actual development of the policy, its formal adoption, its implementation, and even further, its evaluation and continuation or modification. Expertise in the form of policy advice is already widely available in and to public administrations, to well-established professional organizations like medical societies and, of course, to large private-sector organizations with commercial or financial interests in the health sector. We need more health actors to join the fray and move from their traditional position of advocacy to a fuller commitment to the development of policy capacity, with all that it entails in terms of leadership and social responsibility.

Keywords: Policy Capacity, Health Reform, Public Action, Leadership, Evidence, Health Politics

Copyright: (C) 2015 by Kerman University of Medical Sciences

Citation: Forest PG, Denis JL, Brown LD, Helms D. Health reform requires policy capacity. Int J Health Policy Manag 2015; 4: 265-266. doi: 10.15171/ijhpm.2015.85

\section{Article History:}

Received: 9 March 2015

Accepted: 16 April 2015

ePublished: 17 April 2015
$\mathrm{T}$ he importance of leadership for successful policy transformation is universally acknowledged: no social or institutional change can be achieved without an entrepreneur, no major reform without a champion, no great cause without a leader. In the fragmented and complex policy systems of today, as in most successful business ventures, it is difficult to imagine innovation - significant and relevant innovation - without strong leadership to provide inspiration, guidance, and an overall sense of purpose. The area of health reform is no exception.

However, contrary to lapses in leadership, which are widely recognized as a reason for policy inertia and failure, shortcomings in policy capacity are often disregarded. Yet, the best research will be set aside if no one is capable of converting evidence into projects, structures, or regulations. The best plans will fall short if no one is there to pilot the reforms when they meet resistance or bring about unexpected consequences. The most determined leaders will fail if no one can translate their vision into concrete measures or if the resources at their disposal, from funding to information, are scarce and limited.

Policy capacity is the sum of competencies, resources, and experience that governments and public agencies use to identify, formulate, implement, and evaluate solutions to public problems. Policy capacity is concerned with more than the gathering of information and the formulation of options for public action in the initial phases of policy consultation and development. It touches on all stages of the policy process, from the strategic identification of a problem to the actual development of the policy, its formal adoption, its implementation, and even further, its evaluation and continuation or modification.

Even in academic policy analysis, the concept of capacity is not widely understood. In the literature, the approach is still abstract and generic, with a strong emphasis on analytics and planning (1-4). Yet analysis and what it entails - good data, robust models, strong conclusions - cannot alone result in any real change in a health system. Not only must evidence be translated or adapted before it is embraced by decision-makers but it must also be combined with other factors or conditions if it is to result in something concrete and sustainable. Beyond "operations and analysis", to quote Koller (5), reform takes "work, skill, and resources".

Policy capacity depends, to give just one example, on familiar resources like budgets and personnel. Change happens naturally; purposeful change (what we call reform) does not. Without financial resources, there can be no hiring of analysts, no background research, no policy advice, no communication strategy, no monitoring, and no evaluation. Without qualified personnel, the problem is more or less the same, because policy initiatives are highly vulnerable to lapses in competence and dedication.

Capacity is also dependent on the organizations tasked with the development, implementation, and oversight of a policy. Some organizational arrangements are clearly more effective than others, if only because they provide essential continuity to public action, notably during the critical phase of implementation. Moreover, policy renewal and innovation cannot flourish without institutional boundaries and organizational routines to protect them from competition and contestability (6).

Last, but clearly not least, insight and real-life experience are conditions of policy success. So much of the knowledge engaged in a discrete policy intervention turns out to be local, specific, singular. Generic solutions and cookie-cutter approaches may bring prestige and profit to their proponents, but in the end, viable and beneficial transformations will come from those who understand the culture and the context, including the political realities.

\section{Policy capacity in practice}

Policy capacity is a challenge for all sectors, not only for health and social policy. Some methods and approaches are common to all fields of government. The constraints imposed by the social, economic, or political context tend to be felt across the complete 
range of public activities. The political process, with some nuances, is the same, whether the issue is housing or taxation. Where health policy differs, however, is in its substance, which covers a wide body of knowledge.

Ideally, capacity in health policy would combine proved aptitudes for economic and social data analysis and operational research, allied with proper understanding of medical and health realities - including the sociology of illness and health - and communication skills. Yet, the number of variables involved in shaping health at the population, community, and individual levels can be overwhelming. The problems that need to be solved and the solutions that are adopted are intrinsically complex, each with its own mixture of values, science, and uncertainties. The characteristics of the professional landscape are quite broad, from physicians to health lobbyists (7). This universe is too much for one person to master; it might be too much even for a team (8). The solution does not reside in more analytics or methods. Health reform is not a one-time event but rather an ongoing process in which long-term policy goals are achieved despite conflicted political environments and frequent changes in public authorities, staff, and consultants (9). The process cannot succeed without an effective distribution of information about health issues among multiple players and stakeholders.

To draw a simple parallel, in a mature health system, policy capacity is to decision-makers what health literacy is to patients and the public. Making patients active participants in their own care does not require morphing every one of them into a physician or a nurse. Improving policy capacity in health systems does not aim at transforming every decision-maker into a patented policy analyst or every health agency into a think tank. The goal is to raise the level of the policy conversation by making it better informed and more pluralistic.

\section{How to foster policy capacity}

The number of organizations engaged in policy advice is constantly growing. This is the case with think tanks, of course, but a wide range of other organizations such as law and accounting firms have realized that health policy can be a profitable market opportunity. Also noteworthy is those established health organizations that are deciding to invest in policy work, whether to achieve specific goals or to seek public recognition as "senior" players. A traditional stakeholder may be satisfied with providing input whenever policy objectives are formulated and public action is planned, in the early phases of the process; new "policy rich" organizations typically attempt to engage throughout the full policy cycle, including at the stages of implementation and assessment of outcomes (10).

One important role of policy units is to make public authorities aware of the complexity of problems and of the limits of any solution that relies too heavily on any one type of policy instruments (11). This role is facilitated when diverse partners and stakeholders are able to formulate their perspective not as the expression of mere "demands" or "needs" but rather as enlightened contributions to the identification and resolution of the problem. A good consultation can become an occasion to educate decision-makers in the intricacies of a given issue - if they do not trust their officials, they may be willing to listen to other voices informed by experience, common interests, and superior knowledge of the field.

University-based expertise in health policy is also growing in importance and quality. However, with too few exceptions, it is still very much focused on the first stages of the policy process, such as agenda setting or option identification, or on the very last stages, such as outcomes measurement and evaluation. Direct practical experience of policy development and implementation is still unusual among academics, and few would know firsthand how compromises are negotiated, adjustments are made, and decisions are imposed (or not) on stakeholders before being communicated to the public.

Despite some progress, health policy requires an expanding supply of capacity originating from more sources, public or private. Expertise in the form of policy advice is already widely available in and to public administrations, to well-established professional organizations like medical societies and, of course, to large private-sector organizations with commercial or financial interests in the health sector, like pharmaceutical companies. We now need more health actors to join the fray and move from their traditional positions of advocacy to a fuller commitment to the development of policy capacity, with all that it entails in terms of social responsibility and better leadership.

Ethical issues

Not applicable.

Competing interests

Authors declare that they have no competing interests.

Authors' contributions

PGF wrote the editorial based on original research and suggestions developed in collaboration with JLD, LDB, and DH. The four co-authors contributed to all phases of the editorial process.

\section{Authors' affiliations}

${ }^{1}$ Institute for Health and Social Policy, Bloomberg School of Public Health, Johns Hopkins University, Baltimore, MD, USA. ${ }^{2}$ Ecole nationale d'administration publique, Montreal, QC, Canada. ${ }^{3}$ Department of Health Policy and Management, Mailman School of Public Health, Columbia University, New York City, NY, USA. "4Department of Health Policy and Management, Bloomberg School of Public Health, Johns Hopkins University, Baltimore, MD, USA.

\section{References}

1. Gleeson DH, Legge DG, O'Neill D. Evaluating health policy capacity: Learning from international and Australian experience. Aust New Zealand Health Policy 2009; 6: 3.

2. Howlett M, Joshi-Koop S. Transnational learning, policy analytical capacity, and environmental policy convergence. Glob Environ Change 2011; 21: 85-92. doi: 10.1016/j.gloenvcha.2010.10.002

3. Howlett M. Policy analytical capacity and evidence-based policy making: Lessons from Canada. Can Public Adm 2009; 52: 15375. doi: 10.1111/j.1754-7121.2009.00070_1.x

4. Liebman JB. Building on recent advances in evidence-based policy-making. Washington DC: Brookings Institution; 2013.

5. Koller CF. View from here: Learning Chinese. Milbank Memorial Fund Newsletter, 2014. Available from: http://www.milbank.org/ the-view-from-here/learning-chinese

6. Zietsma C, Lawrence TB. Institutional work in the transformation of an organizational field: the interplay of boundary work and practice work. Adm Sci Q 2010; 55: 189-221.

7. Sharfstein JM. Dear health care lobbyists.... Milbank Quarterly 2015; 93: 15-8. doi: 10.1111/1468-0009.12099

8. Franklin GM, Budenholzer BR. Implementing Evidence-Based Health Policy in Washington State. N Engl J Med 2009; 361: 1722-5. doi: 10.1056/NEJMp0907384

9. Forest PG, Denis JL. Real reform in health systems: an introduction. J Health Polit Policy Law 2012; 37: 575-86. doi: 10.1215/03616878-1597430

10. Gen S, Wright AC. Policy advocacy organizations: A framework linking theory and practice. Journal of Policy Practice 2013; 12 : 163-93. doi: 10.1080/15588742.2013.795477

11. Piattoni S. The Theory of Multi-Level Governance. Oxford: Oxford University Press; 2010. 